\title{
Peran Korps Brimob Polri Dalam Penanggulangan Pelanggaran Hukum oleh Geng Motor di Mako Brimob Polda Sumatera Utara
}

\section{The Role of The Polri Brimob Corporation In Committing Law Violations by Motor Gangs On Mako Brimob Polda North Sumatra}

\author{
Aldyan Teoly Telaumbanua1, Marlina ${ }^{2}$, \& M. Citra Ramadhan ${ }^{1 *}$ \\ 1 Program Studi Magister Ilmu Hukum Universitas Medan Area Indonesia \\ 2 Program Studi Magister Ilmu Hukum Universitas Sumatera Utara Indonesia \\ Diterima: 11 juni 2021; Direview: 01 Agustus 2021; Disetujui: 04 Oktober 2021 \\ *Coresponding Email: citra@staff.uma.ac.id
}

\begin{abstract}
Abstrak
Tulisan ini bertujuan untuk mengkaji aturan hukum tentang pelanggaran hukum oleh geng motor, untuk mengkaji peran Korps Brimob Polri dan kendala yang dihadapi dalam penanggulangan pelanggaran hukum oleh geng motor. Masalah difokuskan pada bagaimana aturan hukum tentang pelanggaran hukum oleh geng motor, bagaimana peran Korps Brimob Polri dan kendala yang dihadapi dalam penanggulangan pelanggaran hukum oleh geng motor. Guna mendekati masalah ini dipergunakan teori peran oleh Soerjono Soekanto. Data-data dikumpulkan melalui pedoman wawancara dan dianalisis secara kualitatif. Kajian ini menyimpulkan bahwa tindak pidana pelanggaran hukum oleh geng motor bertentangan dengan Pasal 170 mengenai kejahatan terhadap ketertiban umum, Pasal 351, Pasal 352, Pasal 368 mengenai penganiayaan dan Pasal 510 dan Pasal 511 mengenai pelanggaran ketertiban umum dalam KUHP, bertentangan dengan Pasal 106 dan Pasal 115 dalam Undang-Undang Republik Indonesia Nomor 22 Tahun 2009 tentang Lalu Lintas dan Angkutan Jalan. Peran Korps Brimob Polri dalam penanggulangan pelanggaran hukum oleh geng motor dapat dilihat dengan menggunakan teori Soerjono Soekanto berdasarkan aspek-aspek peranan sebagai norma, peran sebagai individu/norma, dan peran dalam struktur sosial masyarakat. Adapun faktor kendala yang dihadapi brimob adalah pelaku pelanggaran merupakan anak dibawah umur, kurangnya pengawasan orang tua terhadap anak-anaknya dan aksi geng motor biasanya melibatkan banyak massa.
\end{abstract}

Kata Kunci: Peran; Penanggulangan; Pelanggaran Hukum; Geng Motor

\begin{abstract}
This paper aims to examine the rule of law regarding law violations by motorcycle gangs, to examine the role of the Brimob Police Corps and the obstacles faced in overcoming law violations by motorcycle gangs. The problem is focused on how the law rules regarding law violations by motorcycle gangs, what is the role of the Brimob Police Corps and the obstacles faced in overcoming law violations by motorcycle gangs. To approach this problem, Soerjono Soekanto's role theory is used. The data were collected through interview guidelines and analyzed qualitatively. This study concludes that the criminal act of violating the law by motorcycle gangs is contrary to Article 170 regarding crimes against public order, Article 351, Article 352, Article 368 regarding persecution and Article 510 and Article 511 regarding violations of public order in the Criminal Code, contrary to Article 106 and Article 115 in the Law of the Republic of Indonesia Number 22 of 2009 concerning Road Traffic and Transportation. The role of the Brimob Police Corps in overcoming violations of the law by motorcycle gangs can be seen by using Soerjono Soekanto's theory based on aspects of role as a norm, role as an individual/norm, and role in the social structure of society. The constraint factors faced by Brimob are that the perpetrators of violations are minors, the lack of parental supervision of their children and the actions of motorcycle gangs usually involve a large number of people.
\end{abstract}

Keywords: Role; Countermeasures; Violation of Law; Motorcycle Gang

How to Cite: Telaumbanua, A.T., Marlina., \& Ramadhan, M.C. (2021). Peran Korps Brimob Polri Dalam Penanggulangan Pelanggaran Hukum Oleh Geng Motor (Studi Pada Mako Brimob Polda Sumatera Utara). Journal of Education, Humaniora and Social Sciences (JEHSS). 4(2): 1008-1013. 


\section{PENDAHULUAN}

Perilaku kehidupan sehari-hari yang terjadi di tengah masyarakat masih banyak anggota masyarakat yang melakukan tindak pidana. Hal ini terutama disebabkan keinginan-keinginan manusia yang tidak terbatas dan tidak dapat mengendalikan diri untuk tetap menjalani kehidupan sesuai dengan norma-norma yang wajar (Sitorus, Dkk, 2020; Halawa, Dkk, 2020).

Salah satu pelanggaran hukum yang sering terjadi adalah pelanggaran hukum yang dilakukan oleh geng motor, yaitu kelompok masyarakat yang merasa dirinya sebagai superior. Geng motor tersebut pada umumnya adalah kelompok remaja yang sering melakukan pelanggaran hukum sebagai tindakan kenakalan remaja. Secara definisi, geng motor adalah bagian dari suatu kultur (subkultur) masyarakat yang terbentuk dari umumnya remaja putra atau pemuda dengan latar belakang sosial, daerah, ataupun sekolah yang sama, yang mengasosiasikan diri dengan bersepeda motor sebagai wujud ekspresi.

Faktor penyebab munculnya geng motor adalah faktor pendorong yaitu psikololgi anak muda yang senang bergerombol dan membentuk geng yang memiliki kesamaan hobi. Faktor penarik yaitu ruang atau kanal yang menyalurkan hobi atau aktivitas anak-anak muda tersumbat, sehingga muncul kegiatan yang destruktif dan kontra produktif dengan perkembangan psikologi remaja. Vakumnya hukum atau lambatnya respon dari aparat Kepolisian. Kemunculan geng motor tidak secara tiba-tiba, namun butuh waktu panjang untuk berproses, berkonsolidasi untuk menjadi sebuah kelompok yang eksis.

Korps Brigade Mobil atau sering disingkat Brimob adalah kesatuan operasi khusus yang bersifat paramiliter milik Kepolisian Negara Republik Indonesia. Korps Brimob juga dikenal sebagai salah satu unit tertua yang ada di dalam organisasi Polri. Adapun tugas utamanya adalah penanganan terorisme domestik, penanganan kerusuhan, penegakan hukum berisiko tinggi, pencarian dan penyelamatan (SAR), penyelamatan sandera, dan penjinakan bom (EOD). Satuan brimob sebagai komponen besar di dalam Polri bertugas menangani kejahatan berintensitas tinggi, antiteror, huru-hara, dan pengendalian massa. Tetapi peran Korps Brimob Polri dalam penanganan kerusuhan yang diakibatkan oleh pelanggaran hukum yang dilakukan oleh geng motor belum maksimal karena kejadian-kejadian yang disebabkan oleh geng motor selalu saja terjadi dan sangat meresahkan masyarakat.

Data yang diperolah pada Satuan Brimob Polda Sumatera Utara tercatat sepanjang tahun 2019 di Kota Medan telah terjadi 58 (lima puluh delapan) kasus kejahatan yang melibatkan geng motor. Kasus tersebut meningkat bila dibandingkan pada tahun 2018, dimana pada tahun tersebut terjadi 48 (empat puluh delapan) kasus kejahatan yang melibatkan geng motor. Untuk tahun 2020, hingga pertengahan tahun 2020 (per bulan Juni) telah tercatat sedikitnya 40 (empat puluh) kasus kejahatan yang dilakukan oleh geng motor. Dan diperkirakan jumlah kejahatan tersebut akan bertambah pada akhir tahun 2020 .

Geng motor harus diantisipasi sejak dini, apabila segara tidak dibubarkan maka dikhawatirkan kelompok tersebut kian besar menjadi sebuah jaringan kriminal terorganisasi. Kehadiran mereka akan semakin mengganggu ketentraman masyarakat, khususnya yang beraktivitas malam hari. Terlebih, kehadiran mereka akan mengancam masa depan remaja yang diharapkan menjadi generasi penerus untuk memimpin bangsa (Sialagan, Dkk, 2017; Ginting, Dkk, 2018).

Berdasarkan latar belakanga permasalahan yang tersebut di atas, maka yang menjadi tujuan dari penelitiann tesis ini adalah sebagai berikut yaitu:

1. Untuk mengkaji aturan hukum tentang pelanggaran hukum oleh geng motor.

2. Untuk mengkaji peran Korps Brimob Polri dalam penanggulangan pelanggaran hukum oleh geng motor (Studi Pada Mako Brimob Polda Sumatera Utara).

3. Untuk mengkaji kendala yang dihadapi Korps Brimob Polri dalam penanggulangan pelanggaran hukum oleh geng motor (Studi Pada Mako Brimob Polda Sumatera Utara). 


\section{METODE PENELITIAN}

Jenis penelitian dalam penelitian ini adalah yuridis sosiologis yang dengan kata lain adalah jenis penelitian hukum sosiologis dan dapat disebut pula dengan penelitian lapangan, yaitu mengkaji ketentuan hukum yang berlaku serta apa yang terjadi dalam kenyataan di masyarakat, atau dengan kata lain yaitu suatu penelitian yang dilakukan terhadap keadaan sebenarnya atau keadaan nyata yang terjadi dimasyarakat dengan maksud untuk mengetahui dan menemukan fakta-fakta dan data yang dibutuhkan, setelah data yang dibutuhkan terkumpul kemudian menuju kepada identifikasi masalah yang pada akhirnya menuju pada penyelesaian masalah (Silalahi, 2018; Busyro, 2019).

Penelitian ini menggunakan bahan yang diperoleh dari hasil penelitian kepustakaan, dari penelitian kepustakaan dikumpulkan data sekunder yang meliputi bahan hukum primer, bahan hukum sekunder dan bahan hukum tersier. Penelitian normatif, data yang diperlukan adalah data sekunder. Data sekunder tersebut mempunyai ruang lingkup yang sangat luas, sehingga meliputi surat-surat pribadi, buku-buku harian, sampai pada dokumen-dokumen resmi yang dikeluarkan oleh pemertintah (Muhammad, 2014).

Alat pengumpulan data menggunakan studi dokumen dan pedoman wawancara. Data yang diperoleh melalui penelitian kepustakaan maupun data yang diperoleh melalui penelitian lapangan akan dianalisis secara kualitatif. Analisis kualitatif yaitu analisis data dengan mengelompokkan dan menyelidiki data yang diperoleh dari penelitian lapangan menurut kualitas kebenarannya, kemudian dihubungkan dengan teori-teori yang diperoleh dari studi kepustakaan, sehingga diperoleh jawaban dari permasalahan yang diajukan.

\section{HASIL DAN PEMBAHASAN}

\section{Aturan Hukum tentang Pelanggaran Hukum oleh Geng Motor}

Dalam Pasal 2 UU Nomor 2 Tahun 2002 tentang Kepolisian Republik Indonesia, "Fungsi Kepolisian adalah salah satu fungsi pemerintahan negara di bidang pemeliharaan keamanan dan ketertiban masyarakat, penegakan hukum, perlindungan, pengayoman, dan pelayanan kepada masyarakat". Penyelenggaraan fungsi kepolisian merupakan pelaksanaan profesi artinya dalam menjalankan tugas seorang anggota Polri menggunakan kemampuan profesinya terutama keahlian di bidang teknis kepolisian.

Dalam Undang-undang Nomor 22 tahun 2009, maka dapat diketahui adanya pasal-pasal yang mengatur tentang pelanggaran lalu lintas, misalnya pasal 288 yang menegaskan:

(1) Setiap orang yang mengemudikan Kendaran Bermotor di Jalan yang tidak dilengkapi dengan Surat Tanda Nomor Kendaraa Bermotor atau surat tanda coba Kendaran Bermotor yang ditetapkan oleh Kepolisian Negara Republik Indonesia sebagaimana dimaksud dalam Pasal 106 ayat (5) huruf a dipidana paling banyak Rp. 500.000,- (lima ratus ribu rupiah).

(2) Setiap orang yang mengemudikan Kendaraan Bermotor di Jalan yang tidak dapat menunjukkan Surat Izin Mengemudi yang sah ebagaimana dimaksud dalam Pasal 106 ayat (5) huruf b dipidana dengan pidana kurungan paling lama 1 (satu) bulan dan /atau denda paling banyak Rp. 250.000 (dua ratus lima puluh ribu rupiah).

Tindak pidana yang dilakukan oleh anggota geng motor bertentangan dengan KUHP berikut diantaranya:

a. Kejahatan terhadap Ketertiban Umum, Pasal 170

b. Penganiayaan pada Pasal 351, Pasal 352, Pasal 368, Pasal 510, Pasal 511.

\section{Peran Korps Brimob Polri dalam penanggulangan pelanggaran hukum oleh geng motor di Mako Brimob Polda Sumatera Utara}

Geng motor identik dengan kelompok anak-anak muda yang kesehariannya menggunakan sepeda motor dan membentuk kelompok geng. Tetapi dalam aktivitasnya, geng motor cenderung menjadi sumber gangguan bagi ketertiban umum karena suka melakukan pelanggaran hukum di

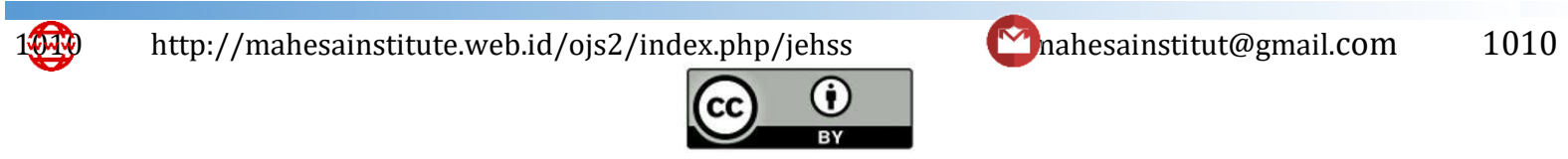


jalanan atau ditempat umum lainnya tanpa memperdulukan kepentingan orang lain (Tambunan, Dkk, 2019; Gintinng, Dkk, 2019).

Pelanggaran hukum yang sering dilakukan geng motor adalah mengganggu ketertiban umum, khususnya jika mereka berkendara erada di jalanan. Geng motor yang melintas di jalan sering menggeber-geberkan suara sepeda motornya hingga meraung-raung memekakkan telinga. Mereka juga berkendara seenaknya tanpa memperdulikan kepentingan orang lain yang sedang menggunakan jalan raya, dimana mereka berkendara seenaknya memenuhi jalanan. Tidak hanya itu, mereka juga sering melakukan pelanggaran terhadap rambu lalu lintas, sehingga sangat berpotensi mengganggu menimbulkan kecelakaan di jalan raya.

Peran Brimob yaitu upaya yang dilakukan oleh anggota Brimop untuk mengubah perilaku para anggota geng motor agar tidak melakukan hal-hal yang mengganggu ketertiban masyarakat. Dalam kaitan ini dianjurkan juga agar para remaja khususnya anak-anak yang masih berada di bawah umur tidak terlibat dalam geng motor. Upayanya dengan mengingatkan agar geng motor tidak menggunakan jalanan sebagai tempat ugal-ugalan, serta tidak mengganggu masyarakat umum yang menggunakan jalan. Anggota Satbrimop juga mengupayakan agar para geng motor tersebut segera meninggalkan jalanan jika terdapat aksi yang dianggap membahayakan masyarakat. Disamping itu, anggota brimob juga mengeluarkan himbauan agar anak-anak yang masih dibawah umur tidak terlibat sebagai anggota dalam geng motor, karena mereka belum mampu membuat keputusan dan masih mudah terpancing secara emosional untuk melakukan pelanggaran hukum.

Sering terjadi bahwa geng motor yang merupakan kumpulan massa benar-benar sudah tidak terkendali karena melakukan tindakan kekerasan kepada barang atau orang di sekitar lokasi atau melakukan tauran, sehingga anggota brimob secara terpaksa harus melakukan penegakan hukum secara represif. Dalam kondisi demikian maka petugas brimob harus melakukan tindakan tegas dengan melakukan tindakan penertiban kepada massa geng motor.

Jika massa geng motor sudah tidak terkendali dalam arti sudah melakukan tindakan pelanggaran hukum seperti perkelahian atau tauran massal, maka aparat keamamanan secara terpaksa harus melakukan tindakan untuk membubarkan massa secara paksa, yaitu dengan memecah massa ataupun menghalau massa geng motor dari lokasi tauran. Tindakan yang dilakukan adalah dengan menembakkan gas air mata ke tengah massa atau bahkan dengan melakukan tindakan pemukulan kepada anggota geng motor.

\section{Kendala yang Dihadapi Korps Brimob Polri dalam Penanggulangan Pelanggaran Hukum oleh Geng Motor di Mako Brimob Polda Sumatera Utara}

Kendala yang dihadapi brimob dalam penegakan hukum terhadap pelanggaran hukum yang dilakukan geng motor adalah jika ternyata pelaku adalah anak di bawah umur. Pelaku anak dibawah umur telah diatur dalam UU SPPA bahwa penganggulangannnya harus mengutamakan penyelesaian di luar pengadilan melalui diversi sehingga brimob harus lebih mengedepankan tindakan persuasive (Silalahi, Dkk, 2019).

Anggota geng motor umumnya adalah anggota keluarga dan memiliki orang tua. Sebagai anggota keluarga, tentu mereka seharusnya mendapat pengawasan dari orang tuanya. Tetapi kenyataannya bahwa banyak orang tua yang tidak lagi mengawasi anak-anaknya (Akhbar, Dkk, 2019).

Geng motor merupakan komunitas yang melibatkan massa dalam jumlah besar. Penanganan massa dalam jumlah besar demikian tentu tidak mudah, sehingga penegakan hukum menjadi terkendala. Dengan jumlah anggota yang mencapai ribuan orang tentu menjadi hal yang sangat sulit untuk melakukan pengendalian. Pengendalian terhadap massa semakin sulit dilakukan jika mereka telah melakukan aksi tauran. Dalam kondisi demikian, kemungkinan adanya korban, termasuk juga korban karena tertembak kemungkinan besar akan ada. 


\section{SIMPULAN}

Berdasarkan pembahasan dan hasil peneitian dari bab - bab sebelumnya, maka penulis akan menarik kesimpulan sebagai berikut: Tindak pidana pelanggaran hukum oleh geng motor bertentangan dengan Pasal 170 mengenai kejahatan terhadap ketertiban umum, Pasal 351, Pasal 352, Pasal 368 mengenai penganiayaan dan Pasal 510 dan Pasal 511 mengenai pelanggaran ketertiban umum dalam KUHP. Disamping itu tindak pidana pelanggaran hukum oleh geng motor sehubungan dengan lalu lintas juga bertentangan dengan Pasal 106 dan Pasal 115 dalam UndangUndang Republik Indonesia Nomor 22 Tahun 2009 tentang Lalu Lintas dan Angkutan Jalan. Peran Korps Brimob Polri dalam penanggulangan pelanggaran hukum oleh geng motor dapat dilihat dengan menggunakan teori Soerjono Soekanto berdasarkan aspek-aspek peranan sebagai norma, peran sebagai individu/norma, dan peran dalam struktur sosial masyarakat. Peran dalam norma yaitu menanggulangi pelanggaran geng motor dengan mengendalikan perilaku geng motor untuk tidak menimbulkan keresahan masyarkat dan tidak melakukan pelanggaran hukum akibat aksinya yang menimbulkan tindakan kriminal. Peran sebagai organisasi yaitu melaksanakan tindakan pengendalian massa berupa pembubaran massa geng motor serta melakukan penangkapan terhadap para pelaku kekerasan, yang dilakukan secara terukur. Peran sebagai struktur sosial masyarakat yaitu dengan memberikan himbauan agar tidak terlibat dalam aksi geng motor, menghimbau orang tua mengawasi anak-anaknya, mengawasi tempat-tempat yang dianggap rawan pelanggaran hukum oleh geng motor, serta menegur atau memperingati pelaku pelanggaran hukum agar tidak mengulangi tindakannya. Adapun faktor kendala yang dihadapi brimob dalam penanggulangan pelanggaran hukum oleh geng motor adalah: pelaku pelanggaran merupakan anak dibawah umur yang dilindungi oleh UU PA dan SPPA, kurangnya pengawasan orang tua terhadap anak-anaknya sehingga banyak anak-anak terutama anak di bawah umur yang terjun ke pergaulan dalam kelompok geng motor, dan aksi geng motor biasanya melibatkan banyak massa hingga sulit dikendalikan dimana terjadinya secara tiba-tiba sehingga petugas brimob kurang persiapan dalam pengendalian massa.

\section{DAFTAR PUSTAKA}

Akhbar, A.T.F, Maswandi \& Kartika A. (2019). Perlindungan Hukum Bagi Anak Dalam Tindak Pidana Pencurian Dengan Kekerasan Yang Mengakibatkan Matinya Korban (Studi Putusan No. 37/Pid.SusAnak/2017/PN. Mdn). JUNCTO, 1(2) 2019: 183-192,

Busyro, M. (2019). Tinjauan Kriminologis Terhadap Preman yang Melakukan Kejahatan (Studi Kasus Polsek $\begin{array}{llll}\text { Batangtoru). DOKTRINA: JOURNAL OF LAW, } & \text { (2), }\end{array}$ doi:https://doi.org/10.31289/doktrina.v2i2.2614

Ginting, H. \& Muazzul. (2018). Peranan Kepolisian dalam Penerapan Restorative Justice terhadap Pelaku Tindak Pidana Pengeroyokan yang Dilakukan oleh Anak dan Orang Dewasa, Jurnal Ilmiah Penegakan Hukum, 5 (2): 32-40.

Ginting, S.Y, Lubis, A.A, \& Zulyadi, R. (2019). Penerapan Sanksi Hukum Tindak Pidana Pemerkosaan Yang Dilakukan Oleh Anak (Studi Putusan No. 65/Pid.Sus-Anak/2017/PN. Mdn). JUNCTO, 1(2) 2019: 166173 ,

Hadi, S, (2010), Metodologi Research, Yayasan penerbit Fakultas Psikologi UGM, Yogyakarta.

Halawa, M., Munawair, Z., \& Hidayani, S. (2020). Penerapan Hukum Terhadap Tindak Pidana Pembunuhan Dengan Sengaja Merampas Nyawa Orang Lain (Studi Kasus Nomor Putusan 616/Pid.B/2015/PN. Lbp). JUNCTO, 2(1) 2020: 9-15

Hasmayni, B, (2016), Perilaku Agresif pada Anggota Geng Motor Ditinjau dari Tingkat Usia dan Suku di Kota Medan, Jurnal Pendidikan Ilmu-Ilmu Sosial, 8(2).

Muhammad, A, (2014), Metode Penelitian Hukum, Citra Aditya Bakti, Bandung.

Siallangan, A.F, \& Siregar, T. (2017). Peranan Kantor Pengawasan Dan Pelayanan Bea Dan Cukai Belawan Dalam Penanggulangan Penyelundupan Satwa Dilindungi Jurnal Ilmiah Penegakan Hukum, 4 (1) 2017: $1-7$

Silalahi, D.H. (2018). Penanggulangan Tindak Pidana Penyalahgunaan Narkotika di SAT RES Narkoba Polres Tebing Tinggi, Jurnal Ilmiah Penegakan Hukum5, (2): 60- 67.

Silalahi, S.D, Munawir, Z \& Syaputra, M.Y.A, (2019). Perlindungan Hukum Bagi Pekerja Kontrak Yang Mengalami Pemutusan Hubungan Kerja Pada Masa Kontrak (Studi Kasus Putusan Nomor : 82/Pdt.Sus-Phi/2016/PN. Mdn). JUNCTO, 1(2) 2019: 174-182,

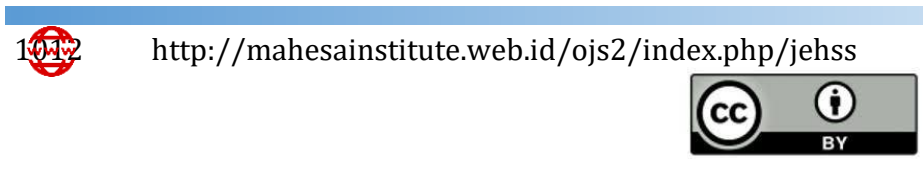

Nyahesainstitut@gmail.com 
Sitorus, J., Zulyadi, R. \& Trisna, W. (2020). Perlindungan Hukum Terhadap Korban Tindak Pidana Pencurian Ditinjau Dari Kajian Victimlogi (Studi Putusan No : 20/Pid.B/2017/PN. Mdn). JUNCTO, 2(1) 2020: 41-50

Soekanto, S, (2012), Sosiologi Suatu Pengantar, Rajawali Pers, Jakarta.

Soekanto, S, (2013), Pengantar Penelitian Hukum, Universitas Indonesia Press, Jakarta.

Tambunan, R, Suhatrizal \& Siregar, T. (2019). Penegakan Hukum Terhadap Tindak Pidana Kepabean Penyeludupan Pakaian Bekas (Putusan No. 237/Pid.B/2016/PN. Tjb). JUNCTO, 1(2) 2019: 158-165,

Perundang-undangan:

Kitab Undang-Undang Hukum Pidana (KUHAP)

Undang-Undang Nomor 2 Tahun 2002 Tentang Kepolisian Negara Republik Indonesia. 